\title{
NA FRONTEIRA DOS MOVIMENTOS SOCIAIS
}

\author{
Alain Touraine*
}

\begin{abstract}
Resumo: Podemos ainda falar em movimento social em sociedades que chamaríamos pós-industriais, às quais muitos observadores chamam sociedade da informação ou da comunicação? A resposta a essa questão preside o emprego que os sociólogos devem ou não fazer da noção de movimento social no mundo de hoje e, em particular, em seus setores economicamente mais modernos. É necessário distinguir claramente, em cada tipo de sociedade, os movimentos sociais propriamente ditos, os conflitos estruturais dessa sociedade que opõem os detentores do poder econômico e social e aqueles a eles submetidos, e os movimentos (históricos) que podem ser claramente definidos pelos conflitos surgidos em torno da gestão da mudança histórica. A primeira noção aparece mais evidente e mais central em estudos sobre a sociedade industrial; entretanto, faz-se necessário descobrir, constantemente, os laços que unem os dois tipos de movimento coletivo.
\end{abstract}

Palavras-chave: movimento social, sociedade industrial, sociedade pós-industrial.

I.1 Propor nova definição e análise dos movimentos sociais, das características e das diversas interpretações elaboradas sobre eles, pode ser julgado como mais pernicioso do que útil. Atualmente, a única razão que me parece justificar um novo exame dessa noção é a introdução de outros elementos no debate. Aqui, duas possibilidades de crítica se apresentam. A primeira delas declara que a idéia de movimento social é menos uma categoria propriamente analítica do que uma categoria de natureza histórica. Isto é, os movimentos sociais estão ligados a um tipo de sociedade, que deixamos para trás, por exemplo, a sociedade industrial. A definição, entretanto, pode ter maior amplitude e, assim, não haver mais necessidade de utilizar a noção de movimentos sociais. Alguns dirão mesmo que é necessário deixar essa noção que nos fecha em um tipo de sociedade que, em grande

* Directeur d'Études à l'École des Hautes Études en Sciences Sociales (EHESS), Paris.

Título original: A la frontière des mouvements sociaux.

Tradução de Ana Liési Thurler.

Artigo recebido em 5 mar. 2006 e aprovado em 13 maio 2006. 
parte, pertence ao passado, dando a impressão de nos oferecer um instrumento de análise geral.

A segunda forma de criticar o uso da noção de movimento social é enfatizar que os fenômenos de globalização ou de mundialização deslocaram consideravelmente os espaços e mecanismos de conflitos, de tal modo que os movimentos sociais merecedores de estudos são aqueles que colocam em questão os mecanismos de globalização que, em larga medida, não suscitam decisões semelhantes àquelas adotáveis por uma "classe dirigente", e não aqueles que se opõem a categorias sociais no interior de um conjunto político ou territorial bem determinado.

Desde logo, indico que essas duas objeções me parecem bem fundadas. Tentarei, então, justificar, sobre esses dois planos principais, a recomendação de suspender o recurso à noção de movimentos sociais, salvo quando se tratar de realidades sociais e históricas já muito estudadas, pois é normal e desejável submeter constantemente a novas análises. É nesse ponto de partida que o título dado a este artigo - que pode chocar por sua violência e seu aparente caráter paradoxal - se apóia.

Para que nenhuma confusão venha retirar o interesse à análise - quer ela seja crítica ou não -, é necessário primeiramente nos entendermos sobre a definição desses fenômenos. Então nos esforçaremos para mostrar que eles, cada vez menos, fazem parte de nosso campo de observação e de análise. É necessário não aplicar a noção de movimentos sociais a qualquer tipo de ação coletiva, conflito ou iniciativa política. É aceitável aplicar análises, ligadas à noção de "resource mobilization" a todas as formas de ação coletiva e de conflito. Aliás, é mais aceitável que as ações coletivas consideradas possam ser analisadas mais em termos de busca de participação no sistema político, mas não há dificuldade de princípio em aplicar essa categoria a todos os tipos de ação coletiva. Em compensação, a sabedoria residiria em reservar o emprego da categoria "movimentos sociais" ao conjunto dos fenômenos que, de fato, receberam esse nome no decorrer de uma longa tradição histórica. O essencial, aqui, é reservar a idéia de movimento social a uma ação coletiva que coloca em causa um modo de dominação social generalizada. Entendo que 
uma relação social de dominação só pode suscitar uma ação que mereça o nome de movimento social se atuar sobre o conjunto dos principais aspectos da vida social, ultrapassando as condições de produção em um setor, de comércio ou de troca ou, ainda, a influência exercida sobre os sistemas de informação e de educação. $\mathrm{O}$ amplo recurso feito à noção de capitalismo, apesar da polissemia desse termo, indica bem o espírito com que foram conduzidos os estudos clássicos sobre os movimentos sociais. Trata-se de estudar os movimentos que colocam em questão condições particulares, isto é, em domínios socialmente definidos, uma dominação que, em sua natureza e em suas aplicações, tem um impacto geral. Essa afirmação conduz diretamente a uma segunda, a saber, que só há movimento social se a ação coletiva - também ela com um impacto maior do que a defesa de interesses particulares em um setor específico da vida social - se opuser a tal dominação. Como essas duas afirmações podem ser combinadas, se não admitirmos conflito entre as partes envolvidas, mas em uma certa representação da sociedade e de suas mudanças, isto é, no interior de um campo ao qual podemos chamar cultura? Recorramos ao exemplo mais clássico. Nas sociedades industriais, o movimento operário e o que podemos chamar de movimento patronal se opõem sobre a utilização dos produtos do trabalho coletivo e dos progressos da produtividade, mas essa oposição se situa no interior de um ethos da civilização do trabalho, da racionalização, de progresso técnico, podendo conduzir - ao menos em princípio - ao progresso social, etc. É o motivo pelo qual proponho, há muito, a seguinte imagem: um movimento social é a combinação de um conflito com um adversário social organizado e da referência comum dos dois adversários a um mecanismo cultural sem o qual os adversários não se enfrentariam, pois poderiam se situar em campos de batalha ou em domínios de discussão completamente separados o que impediria, por definição, tanto o conflito e o enfrentamento quanto o compromisso ou a resolução de conflito. Essa apresentação pode parecer demasiadamente restritiva. $\mathrm{Na}$ verdade, ela não deve ser tomada em sentido muito rígido. Um conflito de impacto geral não se apresenta forçosamente como um conflito geral. É, ao contrário, fácil de observar que os conflitos aparentemente muito limitados, como, por exemplo, os que têm como objeto as condições de trabalho ou as formas de remuneração, valem-se de enfrentamentos com 
impacto geral. Não há necessidade que um conflito social ou que uma ação coletiva se apresente armada de uma ideologia muito elaborada para que possamos concluir a presença de um movimento social. Inversamente, ideologias apelando a conflitos fundamentais na sociedade não são obrigatoriamente manifestações de um movimento social ou de antagonismos sociais. Afinal, a história está repleta de "pequenos" conflitos - com uma ação extremamente limitada na prática histórica -, fundados mais em significados do que em ideologias gerais. Qualquer que seja a flexibilidade com a qual nos empenharmos em referenciar a existência dos movimentos sociais - mediante conflitos ou iniciativas aparentemente mais limitadas -, é necessário considerarmos a definição que apresentei, por corresponder, durante longo período, ao pensamento social, especialmente no período central da sociedade industrial.

Por mais simples que sejam essas definições, elas indicam muito claramente que os movimentos sociais são condutas coletivas e não crises ou formas de evolução de um sistema. Podemos falar de crises ou mesmo da crise geral do capitalismo sem a intervenção da idéia de movimento social. Aliás, é do conhecimento de todos que, durante longas décadas, diversas linhas de pensamento de origem marxista analisaram crises do capitalismo sem incluir a análise dos atores. É importante ser bem explícito. Falarmos sobre movimento social significa colocarmo-nos no ponto de vista dos atores, isto é, dos atores que são, ao mesmo tempo, conscientes do que têm em comum, ou seja, dos mecanismos de conflitos e dos interesses particulares que os definem uns contra os outros. O interesse considerável da noção de movimento social na história da sociologia é haver contribuído para a reflexão passar de um certo objetivismo - insuficiente quando se buscou estudar as condutas - a um estudo claramente definido pela busca de sentido de certas ações, isto é, do sentido atribuído por certos atores à sua ação. Nesse sentido, é necessário dizer, com a mesma clareza empregada até aqui, que a idéia de movimento social se opôs ao pensamento que coloca a razão de ser das condutas coletivas nos problemas estruturais de um certo tipo de sistema, geralmente definido em termos econômicos.

2 A crítica mais direta feita ao uso da noção de movimento social é aquela que a identificou com um aspecto bem preciso e central da 
sociedade considerada. Assim, foi admitido por muitos que o movimento operário tinha culminado no momento em que os métodos de organização do trabalho, e em particular o fordismo, ameaçaram de maneira grave e sistemática a autonomia do trabalho operário e, por conseqüência, atingiram diretamente os operários qualificados. Em todos os países da primeira industrialização, observa-se, no início do século XX uma série de conflitos gerais, freqüentemente introduzindo a idéia de greve geral, que representaram picos na ação "de classe". Em todos os grandes países industriais, ocorreram greves que colocaram mais claramente do que em outros a natureza geral de um conflito formado no domínio do trabalho, mas se aplicando aos domínios mais diversos da vida social. No decorrer de duas pesquisas realizadas há vinte anos de distância, penso ter mostrado que a consciência da classe trabalhadora e, portanto, a força central do movimento operário - ao menos nos países industrializados há mais tempo - esteve ligada ao conflito entre a defesa da autonomia profissional e os métodos de organização ditos científicos do trabalho. Passado esse choque principal, foram retomadas outras definições do trabalho, como nível, estatuto, função, expressões que de nenhum modo remetem a um conflito de impacto geral. O mundo dos empregados, o mundo das categorias operárias muito diferenciadas não produzem mais um movimento social comparável ao que foi o movimento operário da primeira metade do século XX, no caso da Europa, cujas últimas manifestações podemos observar, sobretudo na Itália, com o "outono quente" e, de modo mais limitado, na França, na grande greve Lip, após os acontecimentos de maio de 68 .

3 Inversamente, tanto mais é necessário ter uma visão restritiva do uso da noção de movimento social nas sociedades ditas industriais, tanto mais é necessário aceitar deliberadamente o emprego dessa noção em outras sociedades. O que caracteriza a sociedade industrial é a utilização de uma representação "política" da vida social. Nesse caso, um conflito geral pode se formar em torno da apropriação do poder político. Esse tipo de conflito teve maior visibilidade na Europa. Algumas vezes foram mencionados séculos de revoluções para se falar do período que começou com as revoluções holandesa e inglesa, até a revolução francesa, à qual podemos acrescentar a revolução americana que, antes de tudo, foi uma guerra de independência. Foi também o caso das revoluções bolivarianas, que romperam o liame 
de dependência da maior parte dos países da América com a colonização espanhola.

A aplicação da noção de movimento social a sociedades que se pensaram e se organizaram em termos menos sociais do que políticos, pode também ser feita a sociedades ainda mais distanciadas das sociedades industriais. Se uma sociedade, ela mesma, se concebe, analisa e descreve suas próprias práticas e seus próprios conflitos em termos religiosos, não há nenhuma razão para não aplicar a esses movimentos religiosos a noção de movimento social. É quase ilimitado o campo de aplicação dessa noção - reforçando sua extrema importância - assim como dos conflitos sociais centrais das sociedades industriais e da noção de movimento social, que tem permitido analisálos de maneira adequada.

II Essa evocação muito rápida de sociedades passadas como campo de aplicação da noção de movimento social conduz muito diretamente a uma das duas grandes interrogações que mencionei no início. Podemos ainda falar em movimento social em sociedades que chamaríamos pós-industriais, às quais muitos observadores chamam sociedade da informação ou da comunicação? Na realidade, a resposta a essa questão preside o emprego que os sociólogos devem ou não fazer da noção de movimento social, no mundo de hoje e em particular em seus setores economicamente mais modernos. À primeira vista, não há qualquer razão para não aplicarmos a esse novo tipo societal a análise que usamos para outras sociedades. Não é difícil ver, em diversos países e em tipos de sociedades muito diferentes, conflitos tocando a apropriação da informação e do conhecimento. Estudos sobre mídias foram realizados em hospitais, em escolas para mostrar a existência de conflitos fundamentais concernentes à utilização social da informação. Não há razão de dispensar o conceito de movimento social, recusando utilizá-lo em tipos de sociedade cada vez mais claramente separadas das sociedades industriais, que encontraram suas formas mais clássicas em diversos países, nos séculos XIX e XX.

É, entretanto, impossível não ver uma mudança fundamental de situação. Em todas as sociedades que foram aqui rapidamente 
evocadas, o conflito social tem como eixo a utilização dos recursos criados pela sociedade - seja na ordem dos bens materiais, seja na ordem dos bens simbólicos -, de modo que o êxito ou o fracasso de um movimento social - trata-se de um movimento de dominantes ou de dominados - se traduz por transformação da organização social e, em particular mas não unicamente, da produção. Ao contrário, quando nos situamos na sociedade da informação, não é possível encontrar formas de organização ou de produção que traduzam diretamente uma dominação social. Em outros termos, o triunfo espetacular das tecnologias da informação e da comunicação detém extrema flexibilidade e não são mais instrumentos a serviço de um poder social, ainda que os métodos de organização do trabalho não sejam instrumentos técnicos, mas formas organizacionais de dominação de uma classe sobre outra, do empregador sobre os assalariados. Essa observação se aplica ainda mais facilmente às grandes lutas políticas que precederam os movimentos propriamente sociais, dado que a organização administrativa, o direito e as instituições políticas manifestam, de maneira muito mais direta, as relações de dominação ou uma ação realizada a serviço de interesses e de ideologias claramente identificáveis. Em compensação, quando nos situamos em sociedades da informação e da comunicação não podemos mais nos referir a formas concretas de organização e de produção. Podemos facilmente perceber isso nos discursos dos defensores das empresas, conferindo prioridade à flexibilidade do mercado de trabalho ou à importância da inovação tecnológica. As forças dominantes se definem não mais por seu conteúdo ou formas de vida social, mas por uma capacidade ilimitada de mudança ou de adaptação a um contexto em constante modificação, e, muitas vezes, imprevisível. Por outro lado, é difícil encontrar o equivalente à expressão empregada anteriormente: a defesa da autonomia do trabalho ou da profissão. Não se trata mais de definir um espaço ou um tempo autônomo, e sim de reconhecer a prioridade que deve ser dada à criação - muito mais do que à defesa - de uma autonomia, bem menos profissional ou econômica do que moral. Isto é, a autonomia do próprio indivíduo, considerado como ator ou, para uma expressão mais exata, como sujeito. Em outros termos, os movimentos e os adversários não podem mais ser descritos e compreendidos em termos sociais: o face a face opõe à pura mudança - evocando a 
noção de mercado - a exigência de autonomia, liberdade e responsabilidade da pessoa. Nos dois enfoques, a ordem social é excedida. É a observação mais importante que se pode fazer para compreender as transformações atuais dos movimentos sociais. É a razão pela qual é preferível substituir a expressão "movimentos sociais" por "movimentos culturais", indicando o deslocamento dos conflitos para a ordem simbólica e, ainda mais importante, definindo o que deve ser defendido e o que deve ser combatido, em termos não mais propriamente sociais. Como se, agora, face a face, se encontrassem forças incontroladas como podem ser não somente os movimentos do mercado mas, mais profundamente ainda, os mecanismos conduzindo a catástrofes e enfrentamentos bélicos que excedem largamente as intenções daqueles que acreditam desencadeá-los e dissipá-los. De outro lado, diante dessas forças impessoais, não são transformações sociais ou forças sociais organizadas que estão em cena, mas exigências morais. Ou, como se diz com muito gosto hoje, éticas. Trata-se, entretanto, de moral, à medida que se trata de direitos humanos e da concepção de universalismo desses direitos, mediante formas legais e quaisquer outras. Como se enganar nessas questões? A uma linguagem dominada pelo interesse ou pela estratégia se sucede uma linguagem dominada pela moral, pelo medo de catástrofes, como recurso muitas vezes desorientado com o qual resistir a todas as violências, a todas as crueldades. Lá está, creio, o essencial no que concerne à natureza dos movimentos sociais em nossa sociedade. É necessário ainda falar em movimentos sociais? Creio que sim. Porque se trata ainda de conquistar ou reconquistar um espaço social. Aqueles que querem aumentar o poder das forças impessoais se esforçam em baixar as barreiras sociais, em deixar a regulação feita pelo mercado se exercer tão facilmente quanto possível. Por outro lado, mesmo aqueles que as chamam de modo mais religioso ou escatológico que seja ao que teríamos chamado em outros tempos alma ou humanidade, são cuidadosos em criar pela via jurídica - ou outra - garantias, barreiras que se oponham à destruição do sujeito humano. É necessário que a sociedade não se feche no estudo da linguagem social, isto é, de sua própria linguagem. É indispensável reconhecer ser a linguagem política sobre a vida social do domínio da sociologia, assim como a linguagem "social" sobre a vida social - linguagem própria da sociedade industrial. 
Cabe à sociedade compreender as linguagens políticas e religiosas, mas também as linguagens morais e mesmo as linguagens da tragédia. Nós o sabemos bem. As piores catástrofes, os extermínios, as cenas mais espantosas de crueldade fazem parte da realidade social e não podemos, de nenhuma maneira, desembaraçar-nos de sua violência, falando em casos atípicos, patológicos ou marginais. Quanto mais avançamos na direção dessas sociedades - que são menos sociedades da informação e da comunicação e mais sociedades abertas a todos os ventos, isto é, onde forças não sociais se desencadeiam -, mais se torna importante manter a unidade de uma investigação sociológica, isto é, de uma investigação ao mesmo tempo repousando sobre a idéia de conflito e sobre o que há de comum entre os adversários em conflito. Nas sociedades, onde muitos de nós aprendemos a viver, o comum é a vontade de criar ou de preservar um espaço social. Essa deve ser a razão pela qual temos visto nascer com grande vigor, em diferentes países no decorrer de anos, o tema da reconstrução dos laços sociais.

III É necessário distinguir claramente, em cada tipo de sociedade, os movimentos sociais propriamente ditos que foram evocados, os conflitos estruturais dessa sociedade que opõem os detentores do poder econômico e social e aqueles a eles submetidos, movimentos de outra natureza que, na falta de melhor expressão, designo movimentos históricos e que podem ser claramente definidos pelos conflitos surgidos em torno da gestão da mudança histórica. Falamos do movimento operário como de um movimento social central da sociedade industrial e de movimentos históricos ou políticos como o capitalismo, o socialismo, o comunismo e outros, cujo objeto foi dirigir o processo de industrialização. De um lado, portanto, um conflito interno à sociedade industrial e, de outro lado, um conflito derivado do processo de modernização. Compreende-se facilmente que movimentos sociais e movimentos históricos freqüentemente procurem se unir e mesmo se confundir. Na realidade, a situação mais freqüente é aquela em que os movimentos visam ao controle de um processo de modernização, se apropriam de movimentos propriamente sociais, como estando limitados a um tipo de sociedade. Em muitos países europeus, particularmente na Europa do Sul, os partidos políticos - sejam socialistas, comunistas, anarquistas procuraram, constantemente, impor sua lei aos sindicatos que 
representam os movimentos sociais propriamente ditos. Inversamente, a Europa do Norte foi dominada por partidos sociais-democratas, cuja primeira definição era serem submetidos ao poder sindical. Esse fenômeno foi mais longe na Grã-Bretanha, onde o partido socialista se chamou "Labour" (Trabalhista) e se situou na dependência direta dos sindicatos. Esses fenômenos de dominação ou de confusão têm a maior importância histórica, mas seria necessário que a nenhum preço confundissem o que está separado. Exemplos muito conhecidos de pesquisa em torno da Revolução Francesa insistiram sobre a necessidade de separar movimentos camponeses ou movimentos de "subsistência" de movimentos de inspiração mais urbana, mais burguesa, visando reverter o poder do rei e da aristocracia. Sabe-se que, em sociedades medievais de tipo europeu, sistema senhorial sistema de relações sociais - e sistema feudal - sistema de dependência de vassalos em relação a suseranos - funcionaram independentes um do outro, mesmo se as relações dos senhores com os servos não poderiam ser separadas das relações dos senhores entre eles.

Pode-se, agora, colocar a questão: nas sociedades de informação e da comunicação e, mais geralmente, nas sociedades pós-industriais, há a mesma separação entre os movimentos que se situam no interior de uma estrutura e os que atuam no quadro de um processo de modernização? Mesmo se uma questão tão geral pode provocar uma grande variedade de respostas, conforme os lugares e as circunstâncias, podemos avançar com a idéia geral já anunciada na parte precedente deste artigo: a distância entre movimentos sociais e movimentos históricos - de contestação à elite dirigente da mudança - é muito maior do que nas sociedades industriais. O movimento histórico mais visível neste início do século XXI, o movimento antiglobalização ou altermundialista, aparece como tendo relações distantes com os movimentos sociais propriamente ditos, o que coloca em questão sobretudo o uso do conhecimento na educação, na saúde e outros domínios da vida social. É aqui que ganha todo sentido a oposição entre movimentos sociais que tendem a se tornar movimentos culturais e morais e movimentos históricos que, conduzidos pela modernização, transbordam o quadro do político para colocar em questão uma organização sistêmica e, em particular, redes de comunicação que não podem mais ser imaginadas como simples 
superempresas nacionais. Isso explica a grande dificuldade que encontram os altermundialistas quando tentam estabelecer as ligações com os movimentos propriamente sociais, que resistem a dar importância central à mundialização, em face de seu enraizamento local, social ou profissional.

Essa imagem geral foi inspiradora das análises de dois aspectos complementares dos movimentos sociais e históricos e a cisão dos conjuntos no interior dos quais se situam as análises tão integradas e coerentes quanto possível de todas as formas de ação coletiva que caracterizam um tipo de sociedade e seus processos de modernização.

Ainda que estejamos constantemente tentados a confundir sindicalismo e socialismo ou comunismo, por exemplo, e tentados sobretudo a reuni-los sob o título geral de movimento operário - o que leva somente à confusão - a distância entre o altermundialismo e os movimentos, por exemplo, referidos às relações dos pacientes com o conhecimento e as organizações médicas, essa distância é de tal magnitude que somos tentados a negar a existência de toda relação entre esses dois conjuntos. Reação bem mais preferível do que a reação contrária, com o risco de mascarar o que há de comum, em todos os casos, entre os movimentos que põem em questão uma dominação social e aqueles que atacam o modo de gestão do processo de modernização.

Tudo isso deve conduzir a uma interrogação radical: em tais condições é ainda útil falar em movimento social? Já disse o quanto esses movimentos, um e outro tipo, são cada vez menos definidos no espaço social. Disse, também, que é impossível não chamá-los de movimentos sociais, à medida que seus adversários procuram apoiar seus interesses e seus objetivos sobre mecanismos sociais e instituições que servem de instrumento à reconstrução do espaço social.

Ainda que seja, provavelmente, mais fecundo partir da hipótese de que os movimentos sociais propriamente ditos desapareceram e foram substituídos, de um lado, por puros movimentos históricos e, de outro, por movimentos culturais e sociais, parece-me indispensável recusar essa conclusão perigosa e manter todos os mecanismos intermediários, ainda que fracos, que impeçam uma completa 
separação entre movimentos sociais propriamente ditos e movimentos nascidos da gestão dos processos de transformação histórica.

Chegamos ao ponto extremo do território no qual a noção de movimento social pode ser utilizada. Muitos, com razão, dirão que essa noção aparece mais evidente e mais central em estudos sobre a sociedade industrial. Inversamente podemos lembrar a necessidade de descobrir, constantemente, os laços que unem os tipos de movimentos coletivos. Esse argumento me conduz a concluir sobre a necessidade de manter a referência à noção de movimento social no estudo das sociedades contemporâneas, de quaisquer tipos, mesmo que, à primeira vista, pareçam não exigir a utilização de tais noções. A continuidade da análise sociológica é mais importante do que a observação das diferenças profundas que existem entre um e outro tipo societal.

\section{At the frontier of social movements}

Abstract: Can we still speak about "social movement" in the socalled post-industrial societies, which are also known as societies of information or communication by many observers? The answer to this question depends on the use that sociologists make or do not make of the notion of social movement nowadays, especially in relation to the economically most modern sectors. It is necessary to distinguish very clearly, for every type of society, the central social movements, i. e. the structural conflicts of this society, which express the opposition between the holders of economic and social power and those who are subservient to them, from another type of movement (historical movement), which can be clearly defined by the conflicts arising in relation to the generation of historical change. The first notion appears more clearly and more centrally in the studies of industrial society, but it is important to discover, constantly, the link between the two types of collective movements.

Key-words: social movement, industrial society, post-industrial society 